\title{
Tuning Dynamic Mechanical Response in Metallopolymer Networks through Simultaneous Control of Structural and Temporal Properties of the Networks
}

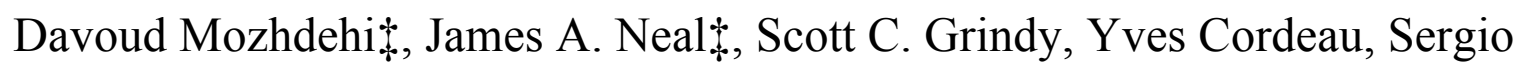 \\ Ayala, Niels Holten-Andersen, Zhibin Guan*
}

\section{Supporting Information}

\section{Table of Contents}

General materials and methods.................................................................................... S2

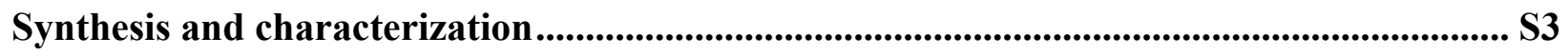

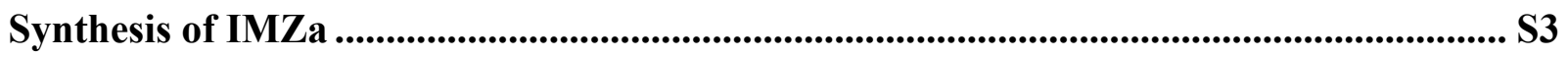

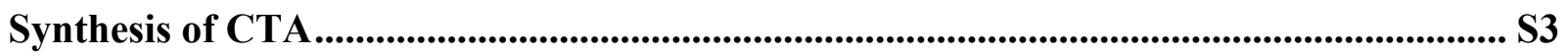

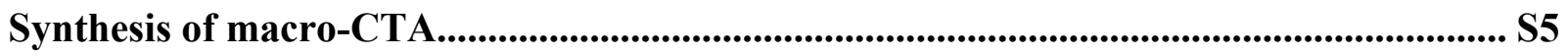

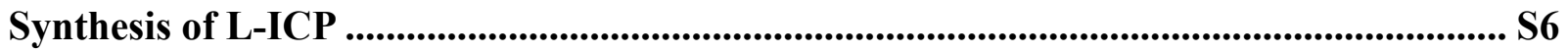

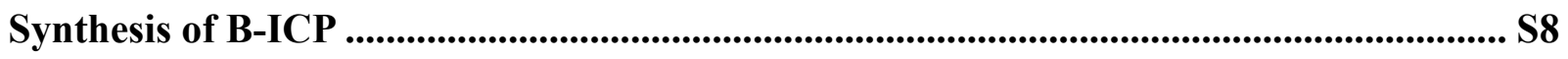

Calculation of theoretical imidazole content ................................................................ S9

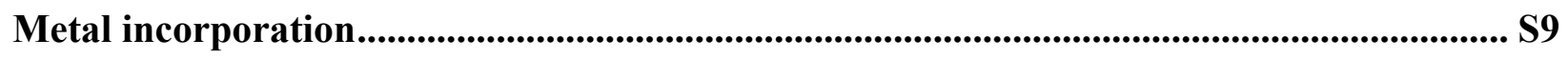

L-ICP metal incorporation for solution rheology .............................................................. S9

Metal incorporation for B-ICP ............................................................................................. S9

Mechanical characterization ..................................................................................... S10

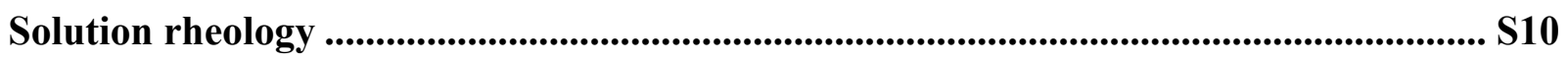

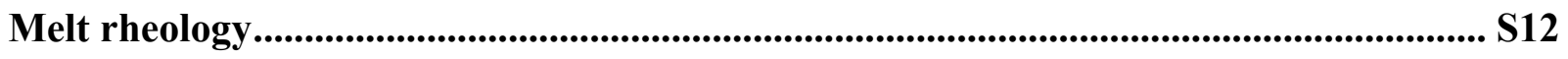

Sample preparation for tensile testing ........................................................................ S13

Mechanical testing procedure ..................................................................................................... S13

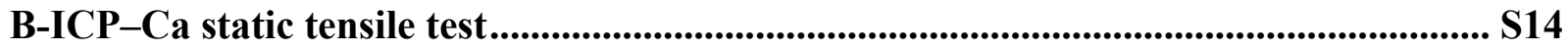

Sample damaging and healing tests.................................................................................... S14

Theoretical calculations ................................................................................................ S15

Calculation of fraction of various $\mathrm{ML}_{\mathrm{n}}$ species ....................................................S15

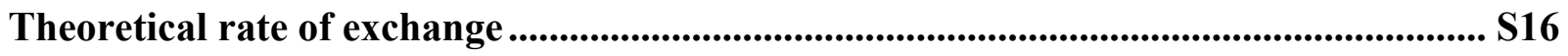

References................................................................................................................................... S17 


\section{General materials and methods}

${ }^{1} \mathrm{H}$ NMR and ${ }^{13} \mathrm{C}$ NMR spectra were recorded at $500 \mathrm{MHz}$ and $125 \mathrm{MHz}$ Bruker Instruments. Chemical shifts were reported in standard format as values in ppm relative to the signal of deuterated solvents. Gel permeation chromatography (GPC) was performed in THF ( $1 \mathrm{~mL} / \mathrm{min})$ using an Agilent LC 1100 Series equipped with Polymer Laboratory's PLgel $5 \mu \mathrm{m}$ mixed-C column to determine molecular weights and molecular weight distributions, $M_{\mathrm{w}} / M_{\mathrm{n}}$, of the macro-CTAs with respect to polystyrene (PS) standards (Varian, Palo Alto, CA). L-ICP and BICP were analyzed by GPC using DMF as eluents supplemented with $0.1 \% \mathrm{LiBr}(\mathrm{w} / \mathrm{v})(1$ $\mathrm{mL} / \mathrm{min}$ ) using an Agilent LC 1100 Series equipped with OHpak SB-803 HQ column from Shodex to determine molecular weights and molecular weight distributions, $M_{\mathrm{w}} / M_{\mathrm{n}}$, with respect to poly(ethylene glycol) (PEG) standards (Sigma Aldrich). GC-MS was obtained on ThermoFinnegen Trace MS+ instrument with DB-5 column $(30 \mathrm{~m} \mu 0.25 \mathrm{~mm} \mu 0.25 \mu \mathrm{m}$ film) with helium gas as carrier on positive EI mode. The mass spectrometry used electron ionization $(70 \mathrm{eV})$ scanning $(1 / \mathrm{sec})$ from $\mathrm{m} / \mathrm{z}$ 50-650.

All metal salts were stored and weighed in a Nitrogen glove box to minimize water absorption and ensure accurate $\mathrm{L} / \mathrm{M}$ ratios. $\mathrm{Cu}\left(\mathrm{NTf}_{2}\right)_{2}$ and $\mathrm{Ca}\left(\mathrm{NTf}_{2}\right)_{2}$ were purchased from Aldrich. $\mathrm{Zn}\left(\mathrm{NTf}_{2}\right)_{2}$ was purchased from Strem Chemicals, Inc. Co(NTf $\mathrm{N}_{2}$ was purchased from Alfa Aesar. $\mathrm{Cu}\left(\mathrm{NTf}_{2}\right)_{2}$ was obtained in hydrate form and the water content, reported in the Certificate of Analysis (determined by Karl Fischer titration), was used to calculate the molecular weight of the copper hydrate.

For butyl acrylate and styrene monomers, inhibitors were removed by passing through basic alumina column prior to polymerization. 4-vinylbenzyl chloride, technical grade, was used as received and was not passed through basic column before polymerization.

Thin layer chromatography, TLC, plates were stained by $\mathrm{KMnO}_{4}$ for presence of double bonds and ninhydrin for the presence of the amine groups. The monomer was purified using CombiFlash ${ }^{\circledR} \mathrm{Rf}+$ automatic column using RediSep Rf Gold ${ }^{\circledR}$ Normal-Phase Silica as described in the monomer synthesis section. 


\section{Synthesis and characterization}

\section{Synthesis of IMZa}

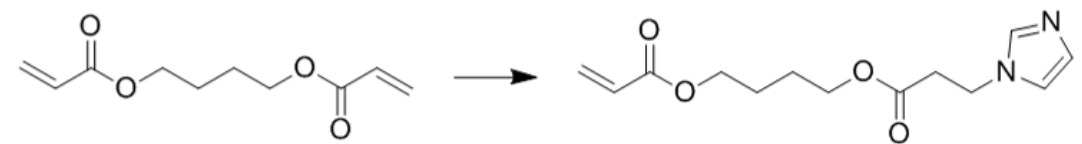

The synthesis of IMZa was carried out as previously described. ${ }^{1}$ The purity of IMZa was confirmed by GC-MS to ensure removal of all unreacted diacrylate starting material which would act as a cross-linking monomer if polymerized. Characterization matched previous literature values. $^{[45]}$

GC Temperature gradient program: initial temperature: $35^{\circ} \mathrm{C}$, ramp/min: $10{ }^{\circ} \mathrm{C} / \mathrm{min}$, final temp: $290{ }^{\circ} \mathrm{C}$.

\section{Synthesis of CTA}

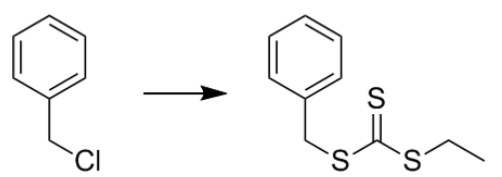

The synthesis of CTA was adapted from a previous procedure. ${ }^{2} \mathrm{~K}_{3} \mathrm{PO}_{4}(21.6 \mathrm{~g}, 94 \mathrm{mmol})$ was suspended in acetone $(100 \mathrm{~mL})$ at room temperature. Ethanethiol $(83 \mathrm{mmol})$ was added via disposable syringe, resulting in a color change to pale yellow. After stirring for 45 min, carbon disulfide (13.1 mL, $216 \mathrm{mmol}$ ) was added to the reaction mixture, resulting in a dark yellow appearance. Next, 4-vinylbenzyl chloride $(10 \mathrm{~mL}, 72 \mathrm{mmol})$ was added to the reaction mixture and allowed to stir for $24 \mathrm{~h}$ at room temperature. The reaction was then poured into chloroform $(200 \mathrm{~mL})$ and extracted with water $(2 \times 100 \mathrm{~mL})$, brine $(1 \times 100 \mathrm{~mL})$, dried over anhydrous $\mathrm{Na}_{2} \mathrm{SO}_{4}$, and the solvent evaporated to afford the desired chain transfer agent. 


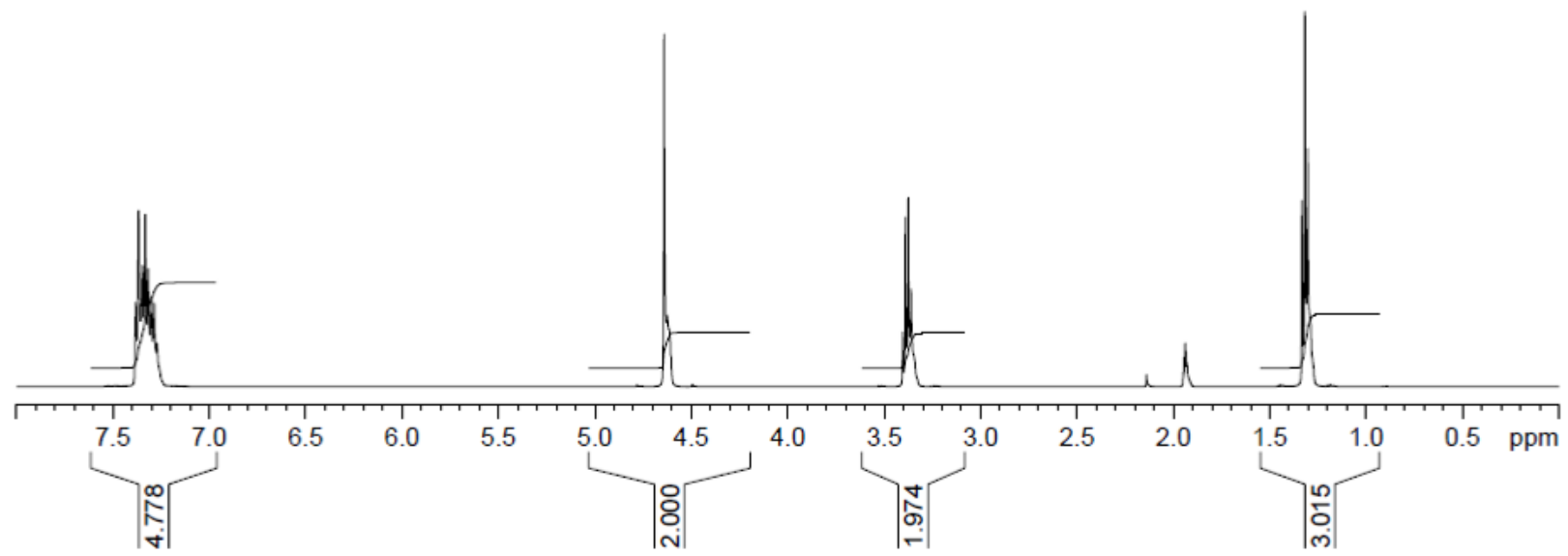

Figure S1. ${ }^{1} \mathrm{H}$ NMR spectrum of CTA $\left(600 \mathrm{MHz}, \mathrm{CD}_{3} \mathrm{CN}, 298 \mathrm{~K}\right)$.

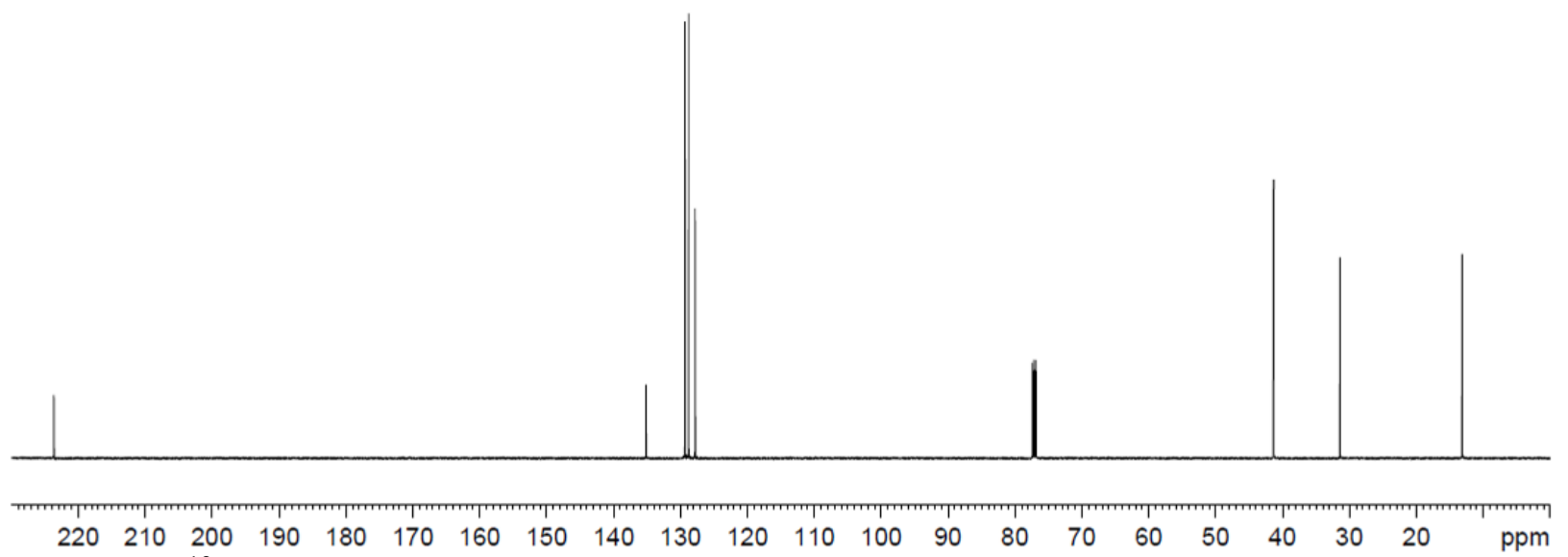

Figure S2. ${ }^{13} \mathrm{C}$ NMR spectrum of CTA $\left(125 \mathrm{MHz}, \mathrm{CDCl}_{3}, 298 \mathrm{~K}\right)$. 


\section{Synthesis of macro-CTA}

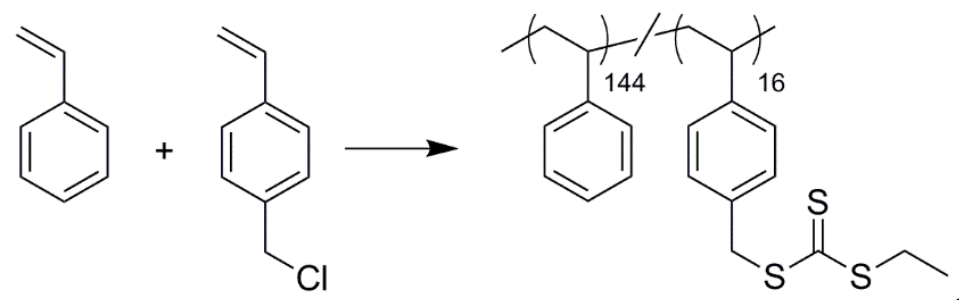

The synthesis of macro-CTA was carried out as previously described. ${ }^{1}$ Macro-CTA was synthesized to possess $10 \%$ initiator and was calculated to contain $0.65 \mathrm{mmol}$ initiator/1 $\mathrm{g}$ of polymer.

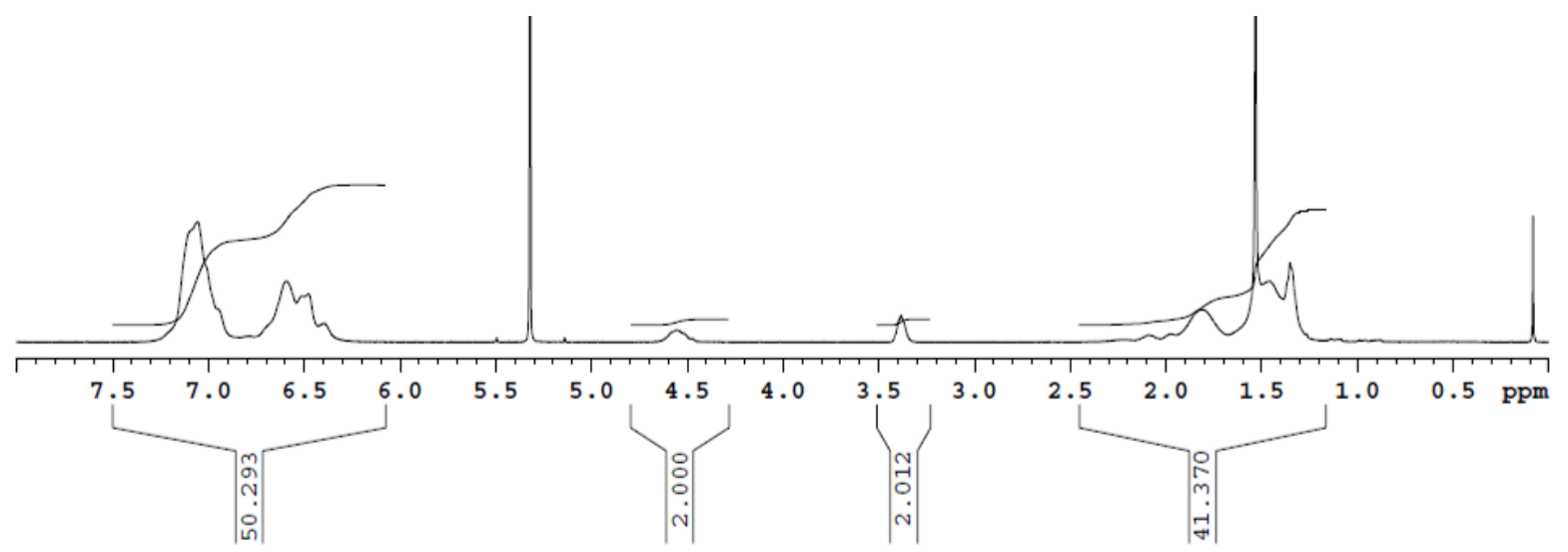

Figure S3. ${ }^{1} \mathrm{H}$ NMR spectrum of macro-CTA $\left(500 \mathrm{MHz}, \mathrm{CD}_{2} \mathrm{Cl}_{2}, 298 \mathrm{~K}\right)$.

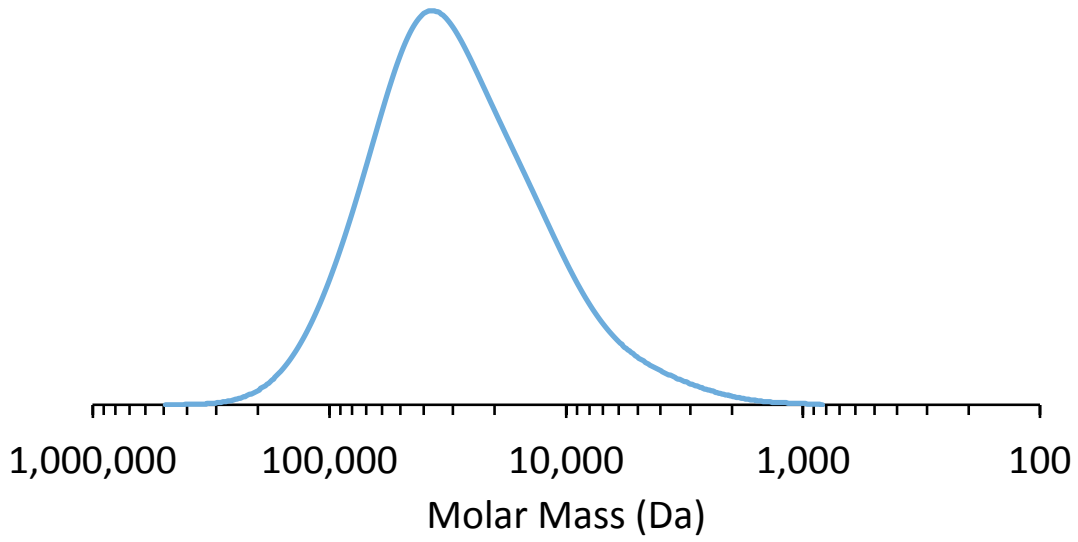

Figure S4. GPC trace of macro-CTA (calibrated using PS standards in THF) $M_{\mathrm{n}}: 19,100$ $M_{\mathrm{w}} / M_{\mathrm{n}}: 2.08$. 


\section{Synthesis of L-ICP}

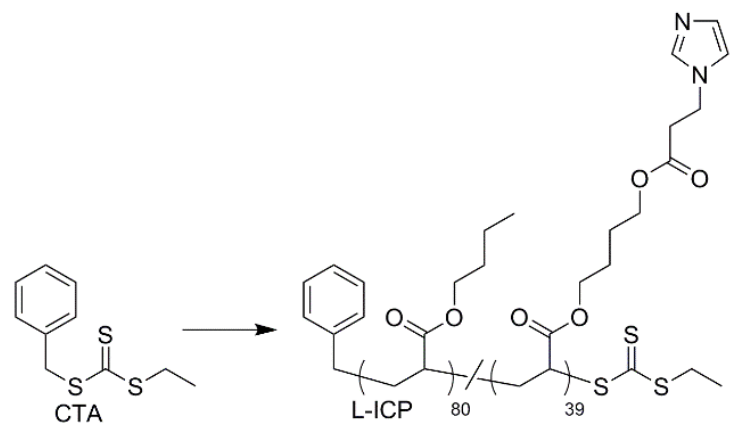

The polymerization of L-ICP was adapted from a previously described procedure. ${ }^{1}$ A representative polymerization procedure follows. Two separate L-ICP batches were combined to provide enough uniform samples for the rheological studies. Using ${ }^{1} \mathrm{H}$ NMR, the IMZa content was calculated to be $1.87 \mathrm{mmol} / 1 \mathrm{~g}$ of polymer.

CTA (129 mg, $0.563 \mathrm{mmol})$ was added to a Schlenk flask. IMZa (10.2 g, $38.3 \mathrm{mmol})$, BA (9.53 $\mathrm{g}, 74.3 \mathrm{mmol}$ ), and $3.2 \mathrm{~mL}$ anisole as NMR internal standard were dissolved in DMF (75.1 $\mathrm{mL}$, $1.5 \mathrm{M}$ with respect to vinyl moiety). AIBN $(18 \mathrm{mg}$ ) was transferred to reaction flask ([Monomer]:[CTA]:[AIBN] = 200:1:0.2). $50 \mu \mathrm{L}$ sample was taken for calculating the conversion using ${ }^{1} \mathrm{H}$ NMR and reaction flask was sealed by a rubber septum. The reaction mixture was then purged with a stream of $\mathrm{N}_{2}$ for $1 \mathrm{~h}$. Schlenk flask was immersed in an oil bath thermostatted at $65{ }^{\circ} \mathrm{C}$. After $190 \mathrm{~min}$, the reaction was removed from the oil bath and was cooled on ice. The conversion was determined via ${ }^{1} \mathrm{H}$ NMR by comparing the integration of vinyl protons with respect to anisole protons $\left(\mathrm{OCH}_{3}\right) .30 \mathrm{mg}$ of 4-methoxyphenol was added as radical inhibitor to the reaction and the reaction mixture was concentrated in vacuo. The residue was transferred to Nalgene centrifuge tubes and the polymer was precipitated in $\mathrm{Et}_{2} \mathrm{O} / \mathrm{Hexane}$ mixture, $(1: 3 \mathrm{v} / \mathrm{v})$ followed by centrifugation at $8500 \mathrm{rpm}$, for $10 \mathrm{~min}$ at $4{ }^{\circ} \mathrm{C}$. The supernatant was decanted and the polymer was dissolved in $\mathrm{CH}_{3} \mathrm{CN}$ and precipitated in $\mathrm{Et}_{2} \mathrm{O} / \mathrm{Hexane}(4: 1 \mathrm{v} / \mathrm{v})$. Finally, the polymer was precipitated in pure $\mathrm{Et}_{2} \mathrm{O}$ three times. The polymer was then dissolved in $\mathrm{CH}_{3} \mathrm{CN}$ and the stock solution was kept at $4{ }^{\circ} \mathrm{C}$. To quantify the concentration of polymer $(\mathrm{mg} / \mathrm{mL})$, known volume of polymer solution was transferred to three oven dried pre-tared 1 dram vials. The solution was then completely dried by placing the vials in pre-heated oven at $80{ }^{\circ} \mathrm{C}$ for $18 \mathrm{~h}$ under reduced pressure $(<1 \mathrm{mTorr})$. The average mass of these three samples was used to calculate the concentration of stock solution. 


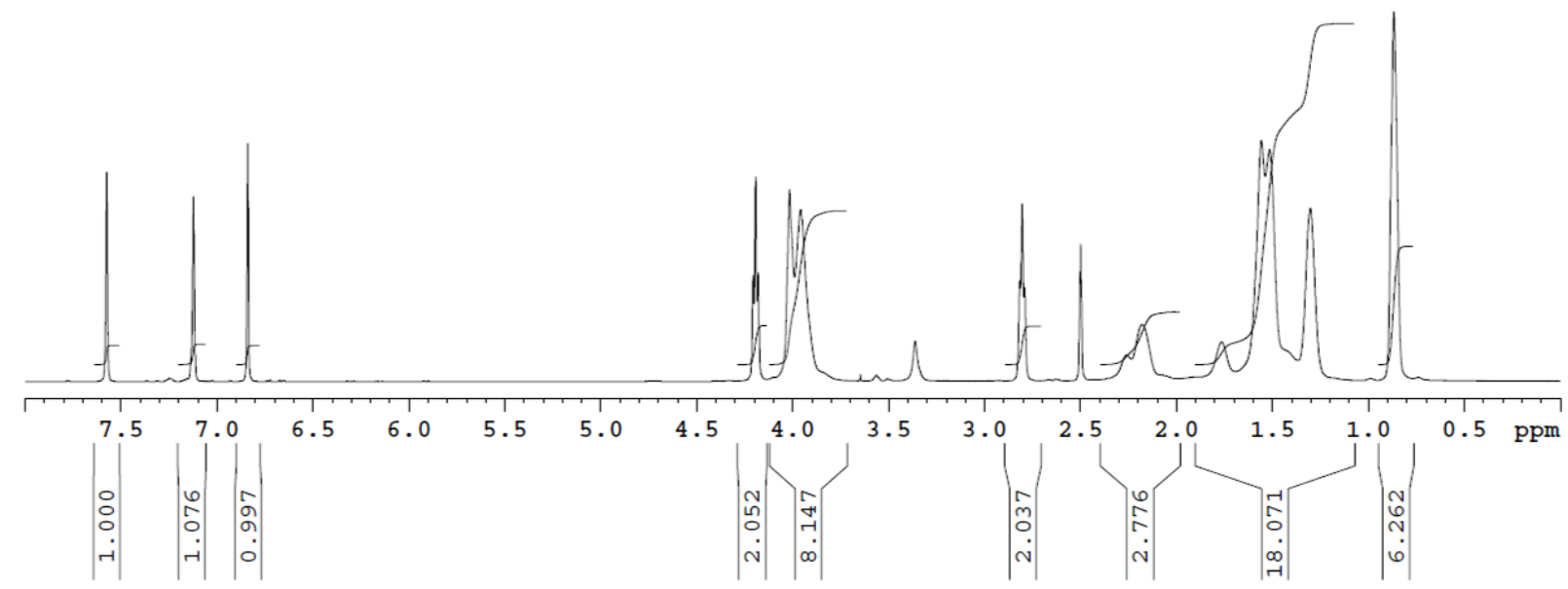

Figure S5. ${ }^{1} \mathrm{H}$ NMR of L-ICP $\left(500 \mathrm{MHz}, \mathrm{DMSO}-d_{6}, 298 \mathrm{~K}\right)$. IMZa incorporation ratio determined by comparison of singlet at $7.6 \mathrm{ppm}$ vs triplet at $0.9 \mathrm{ppm}$.

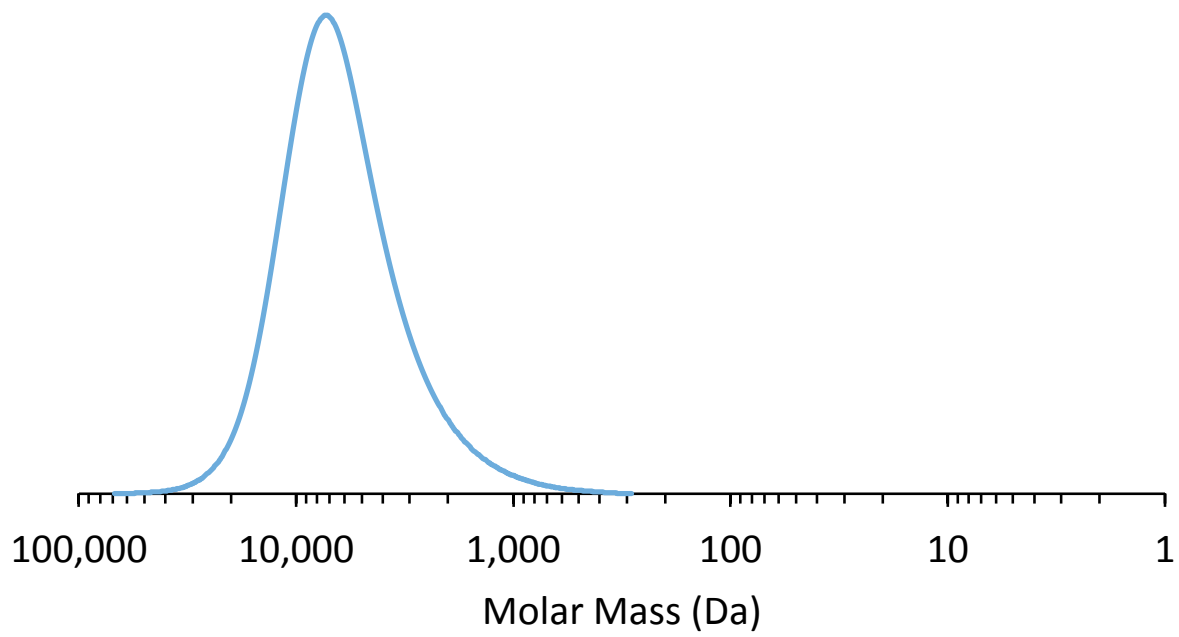

Figure S6. GPC trace of L-ICP (calibrated using PEG standards in DMF) $M_{\mathrm{n}}: 4,900 M_{\mathrm{w}} / M_{\mathrm{n}}$ : 1.53 . 


\section{Synthesis of B-ICP}

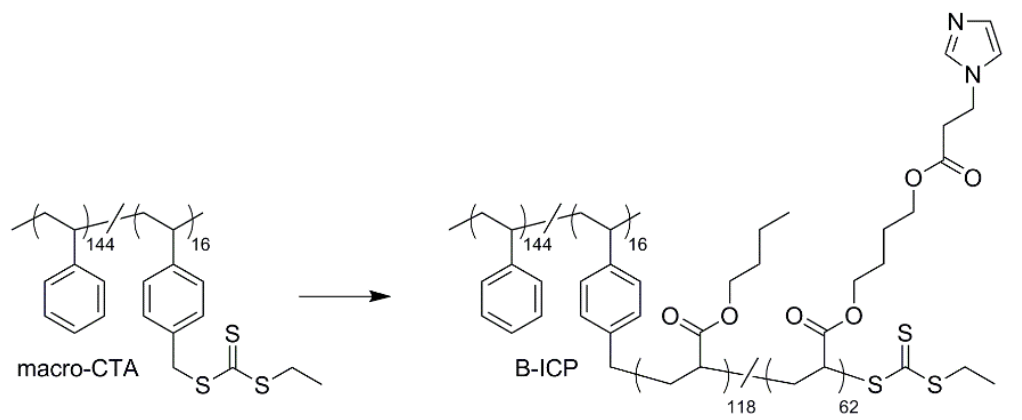

The polymerization of B-ICP was adapted from a previously described procedure. ${ }^{1}$ Two separate B-ICP batches were combined to provide uniform samples to complete tensile testing and selfhealing studies. The average brush contained $34 \%$ IMZa as found via ${ }^{1} \mathrm{H}$ NMR. IMZa content was determined via calculations explained in the previous publication. ${ }^{[45]}$ The IMZa content was calculated to be $1.88 \mathrm{mmol} / 1 \mathrm{~g}$ of polymer.

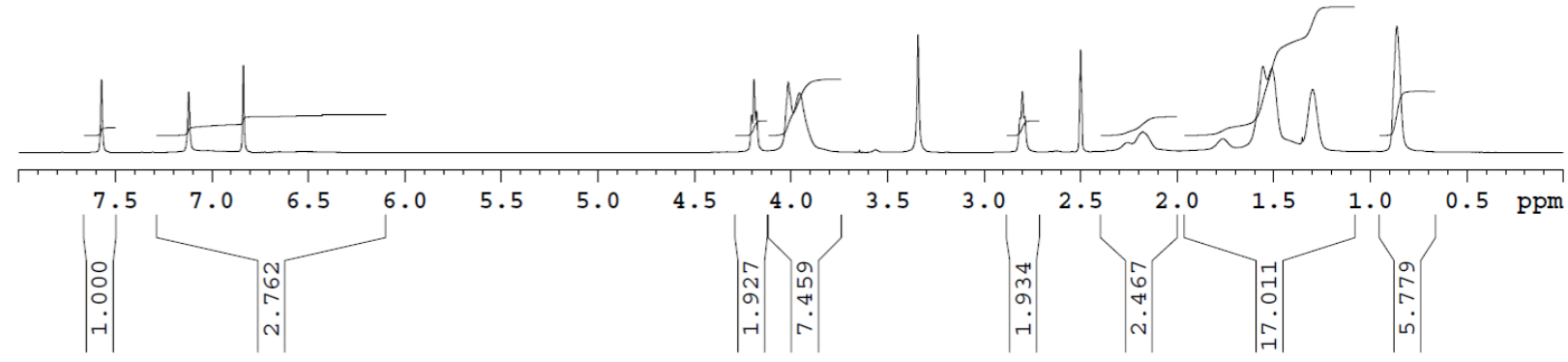

Figure S7. ${ }^{1} \mathrm{H}$ NMR of B-ICP $\left(500 \mathrm{MHz}\right.$, DMSO- $\left.d_{6}, 298 \mathrm{~K}\right)$.

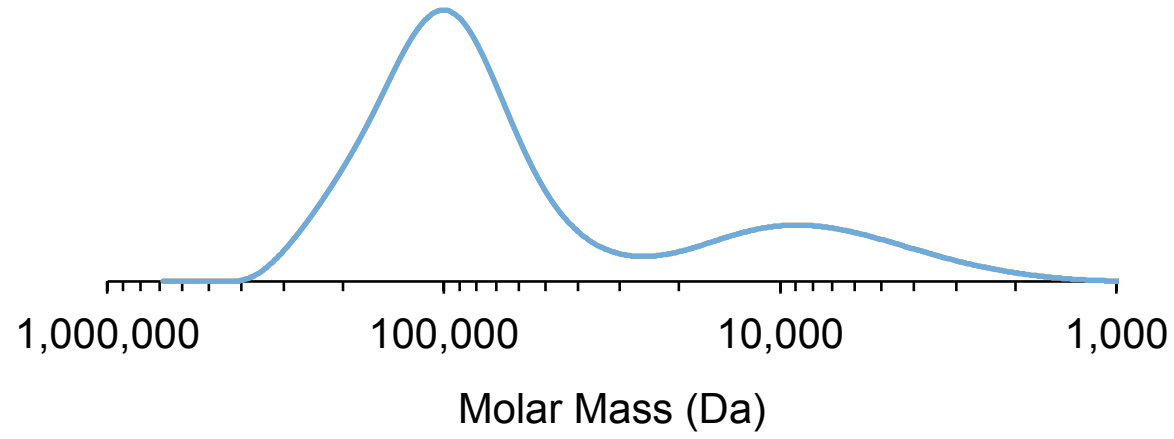

Figure S8. GPC trace of B-ICP (calibrated using PEG standard in DMF) $M_{\mathrm{n}}: 95,600 M_{\mathrm{w}} / M_{\mathrm{n}}$ : 1.23. ${ }^{*} \sim 10 \%$ smaller molecular weight fraction from free chain polymerization is also present. 


\section{Calculation of theoretical imidazole content}

The theoretical imidazole content of each polymer was calculated after characterization of copolymers using ${ }^{1} \mathrm{H}$ NMR. The calculation was carried out as previously reported. ${ }^{[45]}$ Imidazole content for polymers used in this study is reported in Table S1.

Table S1. Theoretical IMZa content (mmol/g) for L-ICP and B-ICP.

\begin{tabular}{cc} 
Polymer & IMZa content $(\mathrm{mmol} / \mathrm{g})$ \\
\hline L-ICP & 1.87 \\
B-ICP & 1.88
\end{tabular}

\section{Metal incorporation}

\section{L-ICP metal incorporation for solution rheology}

The metal di[bis(trifluoromethylsulfonyl)imide] salt of interest was dissolved in $2.3 \mathrm{~mL}$ of $\mathrm{CH}_{3} \mathrm{CN}$ and added slowly (100 $\mu \mathrm{L}$ increments) to a solution of $\mathbf{L}-\mathbf{I C P}$ in $\mathrm{CH}_{3} \mathrm{CN}$ (initial polymer concentration $372 \mathrm{mg} / \mathrm{mL}$ ). After addition of each increment, the polymer solution was agitated with a vortex mixer until a homogeneous solution was obtained. After addition of all metal, polymer solutions were analyzed by rheometer according to procedures described in mechanical characterization section. The final polymer concentration of solution rheology samples was held constant at $85 \mathrm{mg} / \mathrm{mL}$.

\section{Metal incorporation for B-ICP}

The metal di[bis(trifluoromethylsulfonyl)imide] salt of interest was dissolved in $3.0 \mathrm{~mL}$ of $\mathrm{CH}_{3} \mathrm{CN}$ and added slowly (100 $\mu \mathrm{L}$ increments) to a solution of B-ICP in $\mathrm{CH}_{3} \mathrm{CN}$ (starting polymer concentration $171 \mathrm{mg} / \mathrm{mL}$, final concentration $75 \mathrm{mg}$ polymer $/ \mathrm{mL}$ ). After addition of each increment, the polymer solution was agitated with a vortex mixer until a homogeneous solution was obtained. After completing the metal incorporation, the polymer solution was transferred to a Teflon mold and the solvent was allowed to evaporate at ambient conditions $(\sim 5$ h). Next, the samples were further dried in a vacuum oven at $80{ }^{\circ} \mathrm{C}$ for $5 \mathrm{~h}(100 \mathrm{Torr})$. Finally, the sample was dried overnight at $80{ }^{\circ} \mathrm{C}(0.1$ Torr $)$ to ensure complete removal of solvent. Tensile samples were prepared by compression molding at $100^{\circ} \mathrm{C}$. 


\section{Mechanical characterization}

\section{Solution rheology}

Solution rheology data were collected on an AR-G2 Rheometer from TA Instruments (40 mm cone plate with solvent trap, $1.998^{\circ}$ cone angle, $60 \mu \mathrm{m}$ gap). Samples were studied at $0.085 \mathrm{~g}$ polymer/mL in acetonitrile. A frequency sweep was conducted from $0.1-50 \mathrm{~Hz}$ with constant $25 \%$ strain at $20{ }^{\circ} \mathrm{C}$.

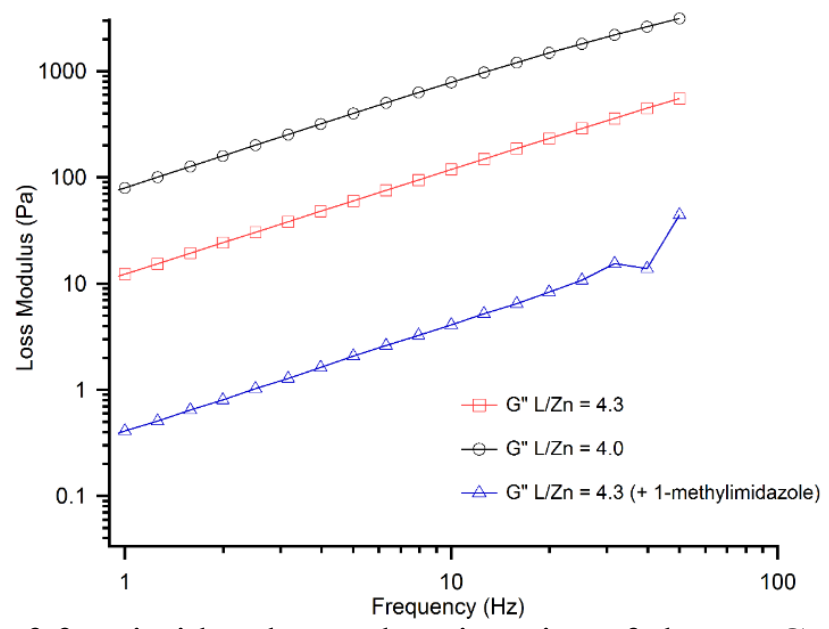

Figure S9. The effect of free-imidazole on the viscosity of the L-ICP-Zn solutions. Solution dynamic viscosity $\left(\eta=\mathrm{G}^{\prime \prime} / \omega\right)$ increases as more $\mathrm{Zn}^{2+}$ is added, $\mathrm{L} / \mathrm{Zn}=4.3$ (red) to $\mathrm{L} / \mathrm{Zn}=4.0$ (black). Addition of $\mathrm{N}$-methylimidazole, reduced the viscosity drastically, $\left(\mathrm{L}+\mathrm{L}^{\prime}\right) / \mathrm{Zn}=4.3$ (blue).

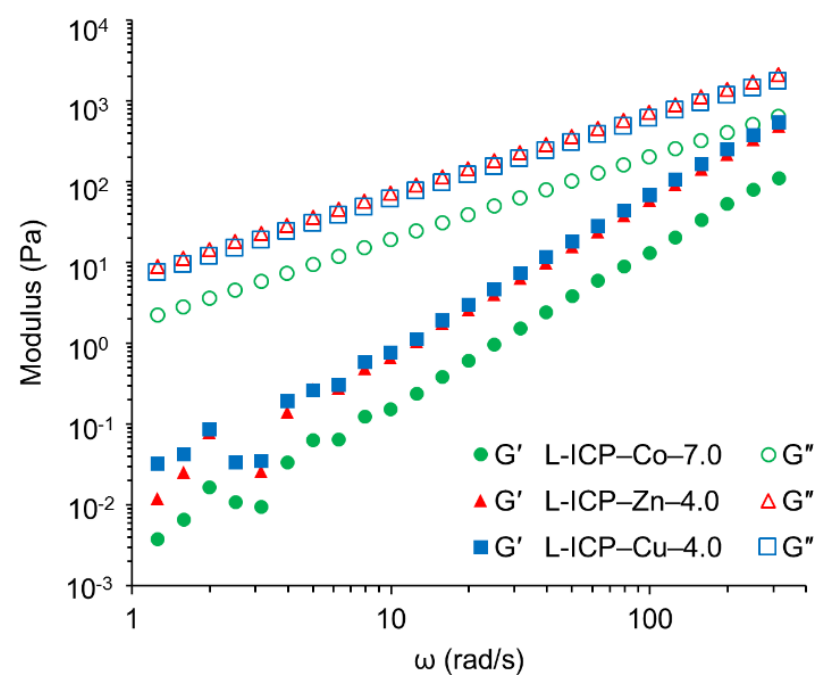

Figure S10. Solution rheological studies of L-ICP-M samples. (a) Representative rheological characterization of L-ICP-M $\mathrm{CH}_{3} \mathrm{CN}$ solutions. The storage (filled symbols) and loss (open symbols) modulus are shown. None of the solutions formed stable gels and behaved as fluids across the experimental range. 
Table S2. Dynamic viscosity of $\mathbf{L}-\mathbf{I C P}-\mathbf{M}$ dissolved in $\mathrm{CH}_{3} \mathrm{CN}$.

\begin{tabular}{cccccc}
\hline \multicolumn{2}{c}{ Zinc } & \multicolumn{2}{c}{ Copper } & \multicolumn{2}{c}{ Cobalt } \\
\hline L/M & $\begin{array}{c}\text { Dynamic } \\
\text { Viscosity } \\
(\text { Pa.s })\end{array}$ & L/M & $\begin{array}{c}\text { Dynamic } \\
\text { Viscosity } \\
(\text { Pa.s })\end{array}$ & L/M & $\begin{array}{c}\text { Dynamic } \\
\text { Viscosity } \\
(\text { Pa.s })\end{array}$ \\
\hline 3.8 & 6.5 & 3.8 & 5.3 & 6.5 & 1.3 \\
4.0 & 7.2 & 4.0 & 6.0 & 7.0 & 2.0 \\
4.2 & 4.5 & 4.2 & 2.7 & 7.5 & 1.5 \\
4.4 & 0.10 & 4.4 & 0.40 & 8.0 & 0.52 \\
4.6 & 0.043 & 4.6 & 0.20 & 10.0 & 0.16 \\
6.0 & 0.020 & 4.8 & 0.090 & 15.0 & 0.022 \\
8.0 & 0.017 & 6.0 & 0.030 & & \\
10.0 & 0.020 & 8.0 & 0.022 & & \\
15.0 & 0.016 & 10.0 & 0.018 & & \\
& & 15.0 & 0.019 & & \\
\hline
\end{tabular}




\section{Melt rheology}

Melt rheology was measured on an Anton-Paar MCR 302 rheometer in a $25 \mathrm{~mm}$ diameter parallel-plate geometry. Frequency sweeps were performed from $\omega=100 \mathrm{rad} / \mathrm{s}$ to $0.1 \mathrm{rad} / \mathrm{s}$ at $\mathrm{T}$ $=80,70,60,50,40,30$, and $20^{\circ} \mathrm{C}$ at $\gamma=1 \%$. Master curves were generated using the timetemperature superposition algorithm of Bae et al. ${ }^{3}$

The complex viscosity is calculated according to the following equation:

$$
\left|\eta^{*}\right|=\frac{\left(G^{\prime 2}+G^{\prime \prime 2}\right)^{0.5}}{\omega}=\frac{\left|G^{*}\right|}{\omega}
$$

Where $\left|\mathrm{G}^{*}\right|$ is the magnitude of the complex modulus and the $\omega$ is the angular frequency.

In our melt rheology experiments, we identify two materials properties, which characterize the basic rheological response: the zero-shear viscosity, $\eta_{0}$, defined as the viscosity in the lowfrequency limit; and the critical shear-thinning frequency, defined as the frequency above which the viscosity begins to decrease. The inverse of the critical shear-thinning frequency $\left(\tau=1 / \omega_{c}\right)$ identifies the terminal relaxation timescale that is proportional to the dynamics of network relaxation. Zero-shear viscosity depends on the polymer cross-linking density and the relaxation rate, which is affected by the dynamics of ligand exchange.

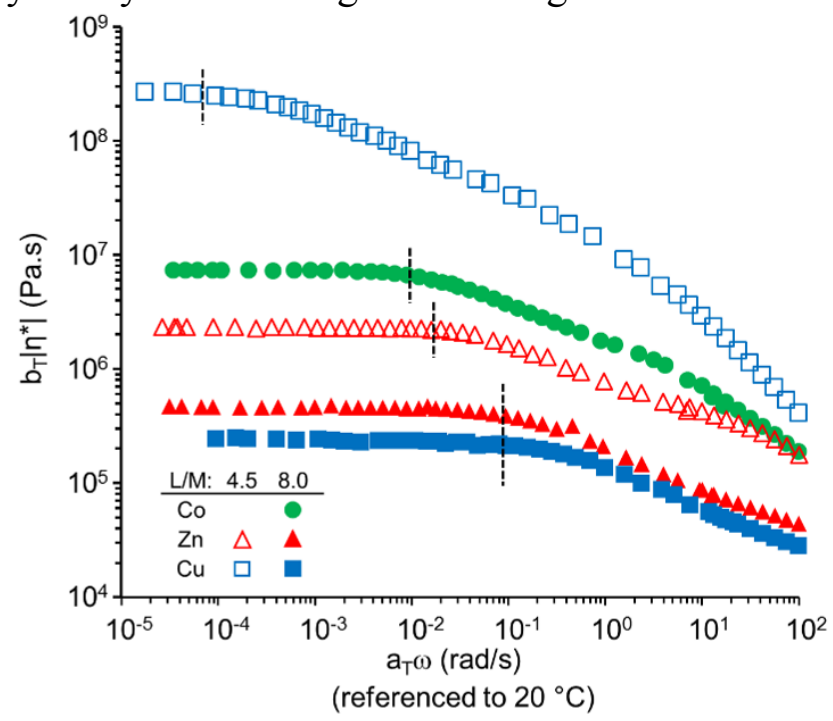

Figure S11. Complex viscosity of L-ICP-M samples at different shear rates referenced to $20{ }^{\circ} \mathrm{C}$ using time-temperature superposition from data taken at $20-80{ }^{\circ} \mathrm{C}$. Critical shear thinning frequency is marked by a vertical dashed line for each sample. At $\mathrm{L} / \mathrm{M}=8.0$ (filled symbols), the zero-shear viscosity and the critical relaxation time scale of L-ICP samples cross-linked with $\mathrm{Cu}^{2+}$ and $\mathrm{Zn}^{2+}$ are similar while the viscosity and the critical relaxation time scale of L-ICP-Co8.0 is over an order of magnitude larger. As the $\mathrm{L} / \mathrm{M}$ ratio decreases from 8.0 (closed symbols) to 4.5 (open symbols), the difference between the viscosity and the critical relaxation time scale of L-ICP-Cu and L-ICP-Zn increases significantly. At L/M = 4.5, L-ICP-Cu is 100-fold more viscous than $\mathbf{L}-\mathbf{I C P}-\mathbf{Z n}$. 


\section{Sample preparation for tensile testing}

B-ICP samples for bulk mechanical characterization were prepared via compression molding. Samples were heated in Teflon molds to $100{ }^{\circ} \mathrm{C}$ and hot pressed. Samples were allowed to quickly cool to room temperature ( $\sim 30 \mathrm{~min})$ while under pressure. Average sample size was 15 $\mathrm{mm} \times 7 \mathrm{~mm} \times 2 \mathrm{~mm}$.

B-ICP samples for self-healing studies were prepared via compression molding at $100{ }^{\circ} \mathrm{C}$, followed by gradual cooling under pressure to room temperature over $12 \mathrm{~h}$. Slow cooling of these samples was carried out to remove residual stress from polymer samples. All samples used for self-healing studies (cut and pristine samples) were processed in this manner.

\section{Mechanical testing procedure}

The mechanical properties of B-ICP samples were measured using an Instron 3365 machine. Standard stress/strain experiments were performed on samples at room temperature. Samples were extended at a rate of $100 \mathrm{~mm} / \mathrm{min}$. Each measurement was repeated at least three times.

Table S3. Summary of mechanical properties for B-ICP-M cross-linked with $\mathrm{Co}^{2+}, \mathrm{Zn}^{2+}$, and $\mathrm{Cu}^{2+}$."

\begin{tabular}{|c|c|c|c|c|c|}
\hline $\mathrm{M}$ & L/M & $\begin{array}{c}E^{a} \\
(\mathrm{MPa})\end{array}$ & $\begin{array}{c}\sigma^{\mathrm{b}} \\
(\mathrm{MPa})\end{array}$ & $\begin{array}{c}\varepsilon_{u l t}^{\mathrm{c}} \\
(\mathrm{mm} / \mathrm{mm})\end{array}$ & $\begin{array}{c}U_{T}^{d} \\
\left(M J / m^{3}\right)\end{array}$ \\
\hline \multirow{4}{*}{$\overbrace{0}^{ \pm}$} & 7.0 & $49 \pm 6$ & $2.8 \pm 0.2$ & $3.5 \pm 0.2$ & $8.2 \pm 0.3$ \\
\hline & 8.0 & $21 \pm 3$ & $1.8 \pm 0.2$ & $5 \pm 1$ & $8 \pm 2$ \\
\hline & 9.0 & $14 \pm 3$ & $1.6 \pm 0.2$ & $6.5 \pm 0.4$ & $8.3 \pm 0.8$ \\
\hline & 10.0 & $10 \pm 1$ & $1.2 \pm 0.1$ & $9 \pm 2$ & $9 \pm 2$ \\
\hline \multirow{5}{*}{ 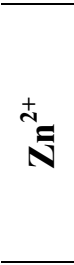 } & 4.0 & $50 \pm 8$ & $8.7 \pm 0.8$ & $1.00 \pm 0.09$ & $5.7 \pm 0.4$ \\
\hline & 4.5 & $14 \pm 1$ & $1.6 \pm 0.1$ & $5.9 \pm 0.6$ & $6.3 \pm 0.7$ \\
\hline & 5.0 & $10 \pm 2$ & $1.9 \pm 0.2$ & $7 \pm 2$ & $10 \pm 4$ \\
\hline & 6.0 & $4 \pm 1$ & $1.5 \pm 0.2$ & $7 \pm 1$ & $8 \pm 2$ \\
\hline & 8.0 & $3.2 \pm 0.4$ & $1.4 \pm 0.1$ & $8 \pm 1$ & $8 \pm 1$ \\
\hline \multirow{5}{*}{$\bar{U}$} & 4.0 & $110 \pm 15$ & $10.2 \pm 0.5$ & $0.79 \pm 0.03$ & $6.3 \pm 0.4$ \\
\hline & 4.5 & $77 \pm 5$ & $5.7 \pm 0.3$ & $1.8 \pm 0.1$ & $9 \pm 1$ \\
\hline & 5.0 & $24 \pm 4$ & $2.99 \pm 0.08$ & $4.1 \pm 0.6$ & $8 \pm 2$ \\
\hline & 6.0 & $7 \pm 2$ & $1.8 \pm 0.3$ & $5 \pm 1$ & $7 \pm 1$ \\
\hline & 8.0 & $3.0 \pm 0.4$ & 1. & .8 & 1 \\
\hline
\end{tabular}

*Strain rate: $100 \mathrm{~mm} \mathrm{~min}{ }^{-1}, 25^{\circ} \mathrm{C}$. ${ }^{a}$ Young's modulus, calculated from the initial slope of stressstrain curves; ${ }^{b}$ ultimate tensile stress; ${ }^{\mathrm{c}}$ ultimate extensibility $\left(\mathrm{mm} / \mathrm{mm}\right.$; ${ }^{\mathrm{d}}$ toughness, calculated by manually integrating the area under the stress-strain curve. 


\section{B-ICP-Ca static tensile test}

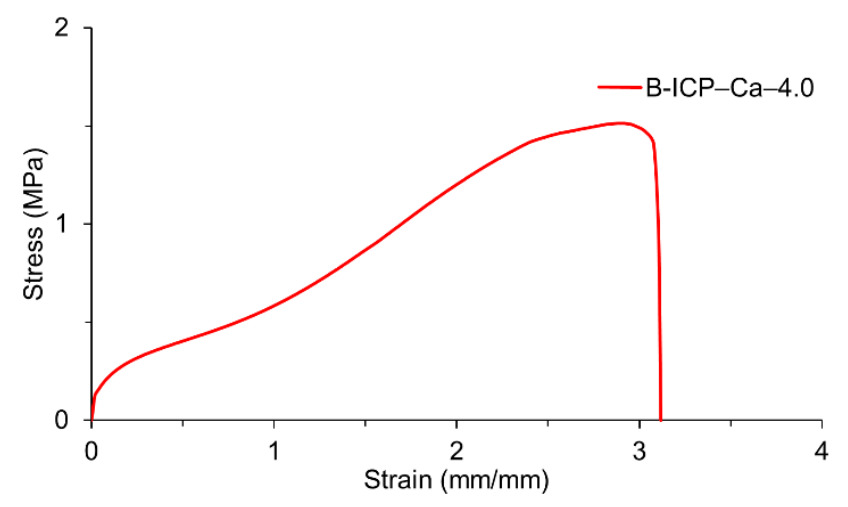

Figure S12. Static tensile tests of B-ICP-Ca-4.0 to demonstrate that the observed B-ICP-M mechanical property changes are not artifacts of ionic interactions. The resulting $\mathbf{B}-\mathbf{I C P}-\mathbf{C a}-\mathbf{4 . 0}$ materials were significantly weaker than B-ICP-Cu and $\mathbf{B}-\mathbf{I C P}-\mathbf{Z n}$ with $\mathrm{L} / \mathrm{M}=4$.

\section{Sample damaging and healing tests}

B-ICP samples were cut with a fresh blade (75\% of width) through the center and subsequently pushed back together for $1 \mathrm{~min}$. Samples were left to stand in air for the duration of the experiment at room temperature. Each measurement was repeated at least three times. 


\section{Theoretical calculations}

\section{Calculation of fraction of various $\mathrm{ML}_{\mathbf{n}}$ species}

The theoretical population of each $M L_{n}$ species was calculated by solving a series of non-linear equations similar to titration problems. Equilibrium constants were used from Table $7(I=0)$ of reference 4, critical survey of literature reports of imidazole-metal binding constants commissioned by the IUPAC ${ }^{[60]}$ A sample calculation is provided below for the $Z n L_{n}$ system.

$$
\begin{gathered}
K_{1}=\frac{[Z n L]}{[Z n][L]} \\
K_{2}=\frac{\left[Z n L_{2}\right]}{[Z n L][L]} \\
K_{3}=\frac{\left[Z n L_{3}\right]}{\left[Z n L_{2}\right][L]} \\
K_{4}=\frac{\left[Z n L_{4}\right]}{\left[Z n L_{3}\right][L]} \\
{\left[M_{0}\right]=[M]+[M L]+\left[M L_{2}\right]+\left[M L_{3}\right]+\left[M L_{4}\right]} \\
{\left[L_{0}\right]=[L]+[M L]+2 \times\left[M L_{2}\right]+3 \times\left[M L_{3}\right]+4 \times\left[M L_{4}\right]}
\end{gathered}
$$

where $\left[M_{0}\right]$ is the initial concentration of metal (zinc) and $\left[L_{0}\right]$ is the initial concentration of ligand. The last two equations describe the mass balance for metal and ligand. For the sake of simplicity, the initial concentration of ligand $\left[\mathrm{L}_{0}\right]$ is assumed to be $1 \mathrm{M}$ and the equations were solved analytically using Mathematica ${ }^{\circledR}$ software for different amount of added metal, $\left[\mathrm{M}_{0}\right]$. The population of each $M L_{n}$ species for $\mathrm{Zn}$ and $\mathrm{Cu}$ at various $\mathrm{L} / \mathrm{M}$ ratios is plotted in Figure $\mathrm{S} 13$.
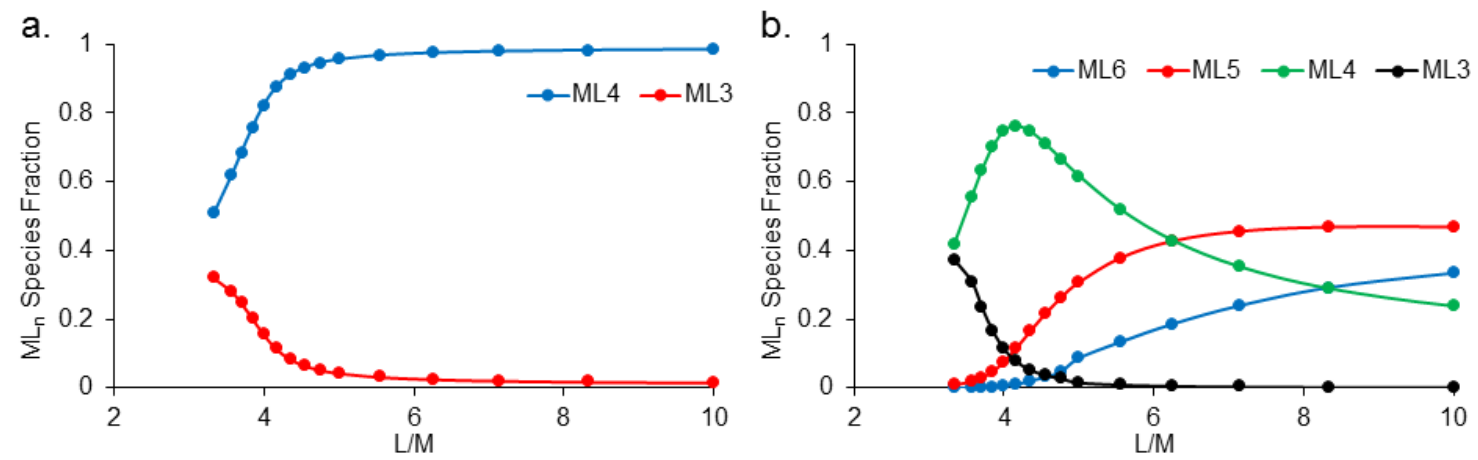

Figure S13. Calcucalted concentration of different $M L_{n}$ species for $M=Z n(a)$ and $C u(b)$ at different $\mathrm{L} / \mathrm{M}$ ratio. 


\section{Theoretical rate of exchange}

The theoretical rate of exchange was calculated based on the concentration of free ligand at various $\mathrm{M} / \mathrm{L}$ ratios for both an associative-dissociative and a strictly dissociative mechanism.

Here, we describe rate of exchange as

$$
\begin{gathered}
R_{\text {associative-dissociatinve }}=k\left[M L_{4}\right][L] \\
R_{\text {dissociative }}=k\left[M L_{4}\right]
\end{gathered}
$$

using known populations of $\left[M L_{4}\right]$ and $[L]$ from the above section, we calculated the rate of exchange at any $\mathrm{L} / \mathrm{M}$ ratio. Figure S14 shows the relationship between the inverse of rate of exchange and L/M ratio. Specifically, a sharp decrease in rate of exchange occurs near L/M $=4$ for the associative-dissociative mechanism (Figure S14a). Conversely, rate of exchange remains constant for the dissociative mechanism (Figure S14b).

This simple calculations also qualitatively predict the sharp increase in the viscosity near $\mathrm{L} / \mathrm{M}=$ 4 for $\mathrm{Cu}^{2+}$ and $\mathrm{Zn}^{2+}$ systems by assuming that the dynamic viscosity is inversely proportional to the rate of the ligand exchange reaction (Figure 2a). ${ }^{5,6} \mathrm{We}$ are excluding the cross-linking density and fraction of inter-chain versus intra-chain connections from this calculation. These topological parameters are mainly affected by the equilibrium constants and are not dependent on the mechanism of ligand exchange.
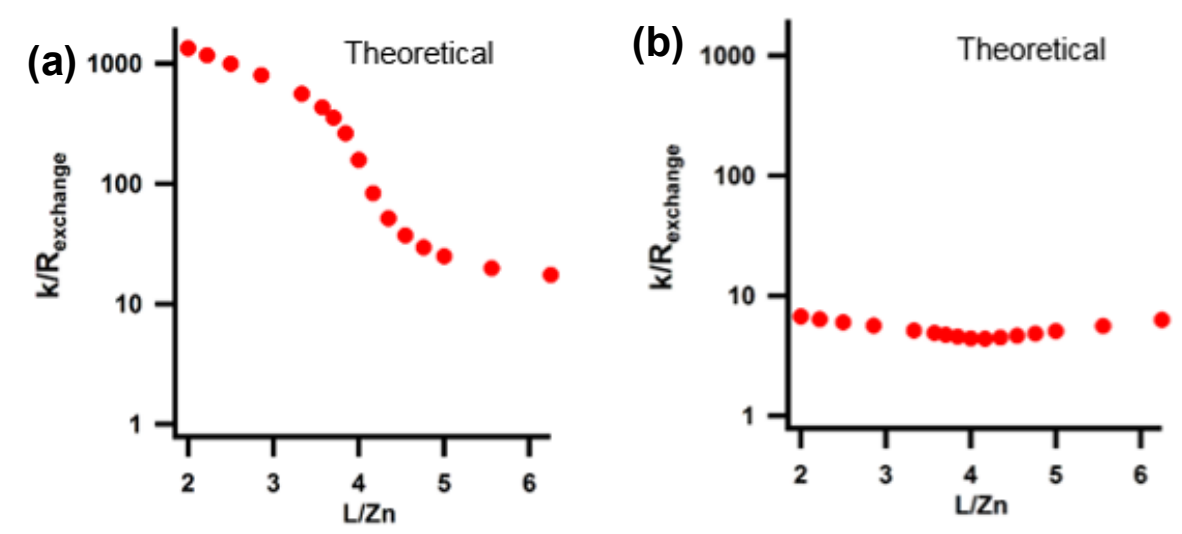

Figure S14. Theoretical dependence of viscosity on L/M ratio for associative-dissociative (a) and dissociative (b) mechanisms for various L/M ratios. Viscosity is inversely proportional to the rate of the ligand exchange. 


\section{References}

(1) Mozhdehi, D.; Ayala, S.; Cromwell, O. R.; Guan, Z. J. Am. Chem. Soc. 2014, 136, 1612816131.

(2) Skey, J.; O’Reilly, R. K. Chem. Commun. 2008, No. 35, 4183.

(3) Bae, J.-E.; Cho, K. S.; Seo, K. H.; Kang, D.-G. Korea-Australia Rheol. J. 2011, 23 (2), 81-87.

(4) Sjöberg, S. Pure Appl. Chem. 1997, 69 (7), 1549-1570.

(5) Yount, W. C.; Loveless, D. M.; Craig, S. L. Angew. Chem. Int. Ed. Engl. 2005, 44 (18), 2746-2748.

(6) Yount, W. C.; Loveless, D. M.; Craig, S. L. J. Am. Chem. Soc. 2005, 127 (41), 1448814496. 